\title{
The Climate Change Space Influences Agricultural Production In Northeast China
}

\author{
Pan Tiefu \\ Laboratory of Agrometeorology \\ Jilin Academy of Agricultural Sciences \\ (Gongzhuling, Jilin Province, 136100 China)
}

\begin{abstract}
The climate in Northeast China has been growing warmer and the rainfall in central and northern parts of Northeast China has decreased. Agricultural production in Northeast China has changed greatly. Thus, appropriate measures should be taken.
\end{abstract}

Key words: climate change, temperature, rainfall, crop yields.

\section{Atmospheric temperatures in Northeast China are increasing.}

From sorting out and analyzing the data of yearly average atmospheric temperature of Shenyang, Changchun and Harbin from 1909 to 1990, it can be seen that the temperature values in Northeast China are gradually increasing (Figure 1, Table 1).

Temperatures at Shenyang (in the southern part), Changchun (in the central part) and Harbin (in the northern part) have been increasing at $+0.0185^{\circ} \mathrm{C},+0.0124^{\circ} \mathrm{C}$, and $+0.01495^{\circ} \mathrm{C}$ per year, respectively. These rates differ highly significantly from the assumption of no temperature increase. Besides Shenyang, Changchun and Harbin, the temperature at other places is also increasing and yearly average temperatures in the 1980 's were about $1.0^{\circ} \mathrm{C}$ higher than that in the 1950 's, which was similar among the three places.

Temperature increase is different in different seasons. According to the meteorological data from Changchun between 1909 and 1990, average temperatures in January and in the period between December and February increased at a rate of $+0.02065^{\circ} \mathrm{C}$ and $+0.0182^{\circ} \mathrm{C}$ per year, respectively, which reached significant levels. Temperature increases in winter have been higher than in other seasons. Average temperatures in April have been increasing at a rate of $+0.0105^{\circ} \mathrm{C}$ per year, which is highly significant and lower than the changes in winter. Average temperatures in October have been increasing at a rate of $+0.00685^{\circ} \mathrm{C}$ per year, which is less than in April. Average temperatures in the growing season (May to September) have been increasing at a rate of $+0.00282^{\circ} \mathrm{C}$ per year, which is not significant. Average temperatures in July have been decreasing at a rate of $-0.00959^{\circ} \mathrm{C}$ per year which is significant (Table 2).

In view of this, the climate in Northeast China is growing warmer, mainly in winter, secondly in spring, thirdly in autumn though this is not clear in the growing season. Because of the temperature increases in spring and autumn, the frost-free period has grown longer. Temperatures in the hottest month (July), however, have tended to decrease. 
2. Rainfall in the middle part and the northern part of Northeast China has been gradually decreasing.

From analyzing rainfall data from Shenyang, Changchun and Harbin between 1909 and 1990, it can be seen that rainfall changes at these locations are different (Figure 2, Table 1).

Yearly rainfall in Changchun has been decreasing at a rate of $-1.2191 \mathrm{~mm}$ per year, which is significant.

It has been decreasing at a rate of $-0.6348 \mathrm{~mm}$ per year in Harbin, which is not significant.

In Shenyang, it has been increasing slightly at a rate of $+0.1372 \mathrm{~mm}$, which is not significant.

In some regions, for example in the most of plain areas, rainfall has been decreasing and in other regions it has been increasing.

Seasonal changes in rainfall: Taking Changchun as an example, rainfall from May to September between 1909 and 1990 decreased at a rate of $-0.79353 \mathrm{~mm}$ per year, which was not significant . Rainfall from December to February decreased at a rate of $-0.1149 \mathrm{~mm}$ per year, which is highly significant (Table 2). Therefore, rainfall decreases from December to February are small, though the original rainfall from December to February was also small. Thus, the calculating relative rate of rainfall decrease, the rate from December to February is much greater than that from May to September.

\section{To make use of the advantages and avoid the disadvantages resulting from climate change and to take appropriate measures.}

The climate in Northeast China is cold, so a warmer climate is favourable for agricultural production. Low temperature harm, which imperiled agricultural production in the past, has not occurred over the past 15 years in large areas. A warmer climate makes agricultural production in Northeast China greatly changed. Crop areas, such as rice and maize, which have high yields and are adapted to high temperatures, have been enlarged. In 1949, the areas of rice and maize comprised $24.5 \%$ of the total crop areas. In 1988 the area of rice and maize were 49.4\%. From statistical analysis, the coefficient of correlation between the rice yield in Northeast China and temperature from May to September is +0.623 ; for maize, the coefficient is +0.687 . These two coefficients are all highly significant. The proportion of high yields and long growth period varieties has also increased. The growth period of varieties is 7-10 days longer than the past varieties. At present, the seeding time is 7-10 days earlier than in the past. Total grain output in Northeast China has increased by $233.6 \%$ from the 1949 's total of 14 million 115 thousand tons to the 1988's 47 million 516 thousand tons. In view of this, one should make use of the advantages of climate changes and take appropriate measures to obtain greater harvest. Also one should pay attention to the climate changes over the years and allow for unforeseen circumstances to avoid losses.

Rainfall has decreased gradually in the middle and the northern parts, so one should pay attention to fight droughts and to preserve the moisture of the soil in the middle and west parts and one should extend the rice culture technology of water conservation to obtain high and stable yields. Also one should pay attention to forests, 
grasslands and reducing circumstance pollution, for the purpose of retaining fine climatic circumstances and bringing benefit to the people.

\section{References}

Cheng Chunshu, 1991: Climate and Agriculture of China, Meteorological press, Beijing, China.

Pan Tiefu, 1990: Agroclimatic long-range forecast in Jilin Province of China. China Agricultural Scientech Press, Beijing, China.

Table 1 . Tendency of the yearly average temperature changes and yearly rainfall change in Shenyang, Changchun and Harbin (1909-1990)

\begin{tabular}{|l|l|l|l|l|}
\hline \multicolumn{1}{|c|}{ Type } & \multicolumn{1}{c|}{ Place } & \multicolumn{1}{c|}{ B value } & \multicolumn{1}{c|}{ T value } & \multicolumn{1}{c|}{$\begin{array}{c}\text { Significant } \\
\text { level }\end{array}$} \\
\hline Yearly average & Shenyang & $+0.0185 \mathrm{X}$ & 6.816 & $<0.001$ \\
temperature & Changchun & $+0.0124 \mathrm{X}$ & 4.119 & $<0.001$ \\
$\left({ }^{\circ} \mathrm{C}\right)$ & Harbin & $+0.01495 \mathrm{X}$ & 4.618 & $<0.01$ \\
\hline Yearly rainfall & Shenyang & $+0.1372 \mathrm{X}$ & 0.156 & - \\
$(\mathrm{mm})$ & Changchun & $-1.2191 \mathrm{X}$ & 2.033 & $<0.05$ \\
& Harbin & $-0.6348 \mathrm{X}$ & 1.086 & -- \\
\hline
\end{tabular}

Table 2. Tendency of the monthly average temperature change and monthly rainfall change in Changchun (1909-1990)

\begin{tabular}{|l|l|l|l|l|}
\hline \multicolumn{1}{|c|}{ Type } & \multicolumn{1}{|c|}{ Month } & \multicolumn{1}{c|}{ B value } & \multicolumn{1}{c|}{ T value } & \multicolumn{1}{c|}{$\begin{array}{c}\text { Significant } \\
\text { level }\end{array}$} \\
\hline & Jan. & $+0.02065 \mathrm{X}$ & 1.854 & $<0.05$ \\
Average & April & $+0.0105 \mathrm{X}$ & 2.906 & $<0.01$ \\
temperature & July & $-0.00959 \mathrm{X}$ & 2.017 & $<0.05$ \\
$\left({ }^{\circ} \mathrm{C}\right)$ & Oct. & $+0.00685 \mathrm{X}$ & 1.118 & - \\
& May-Sept. & $+0.0028 \mathrm{X}$ & 1.087 & - \\
& Dec.-Feb. & $+0.0182 \mathrm{X}$ & 2.764 & $<0.01$ \\
\hline Rainfall & May-Sept. & $-0.7935 \mathrm{X}$ & 1.410 & -- \\
& Dec.-Feb. & $-0.01105 \mathrm{X}$ & 2.780 & $<0.01$ \\
\hline
\end{tabular}




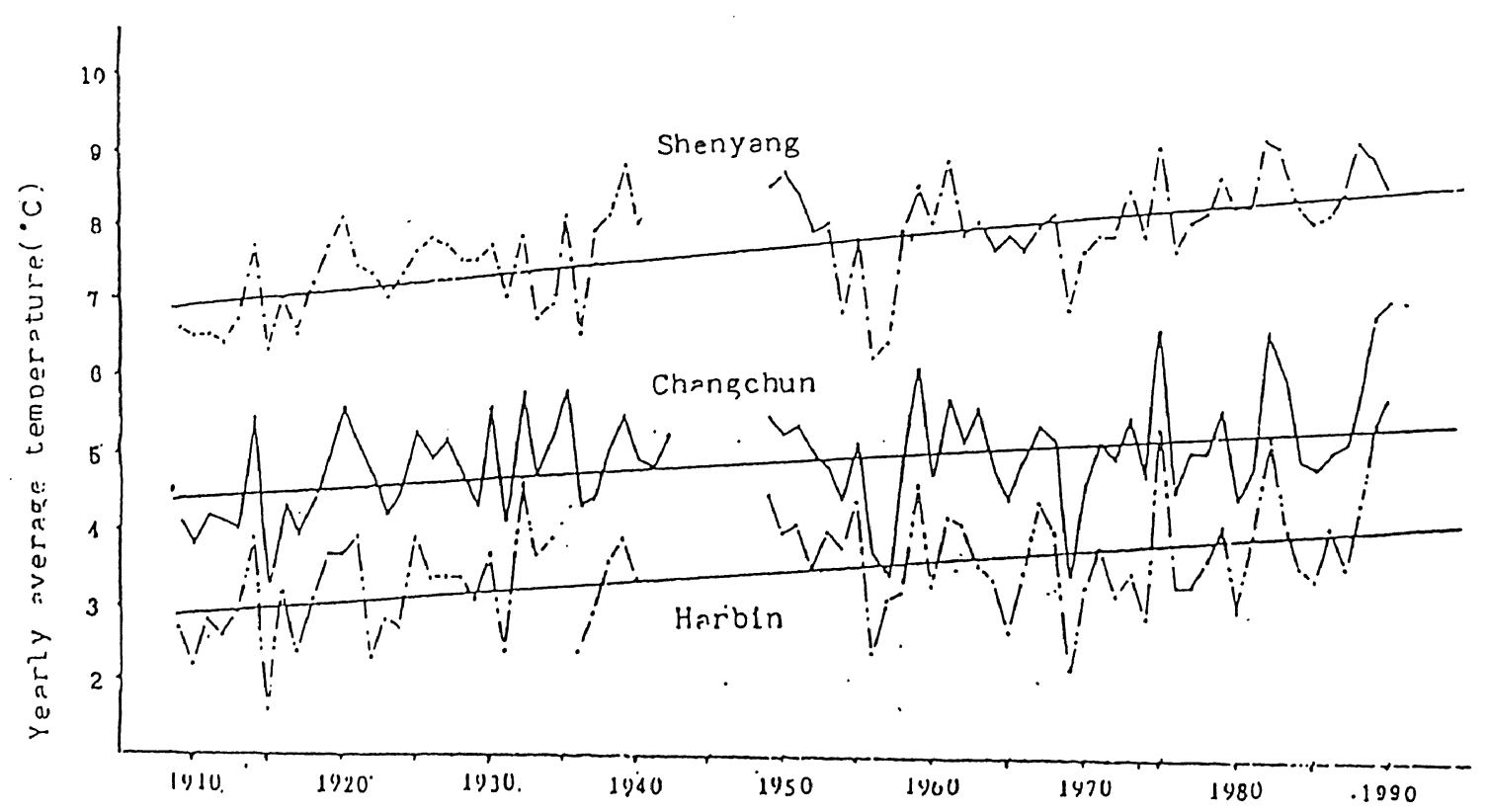

Figure 1. Yearly average temperature $\left({ }^{\circ} \mathrm{C}\right)$ change in years in Shenyang, Changchun

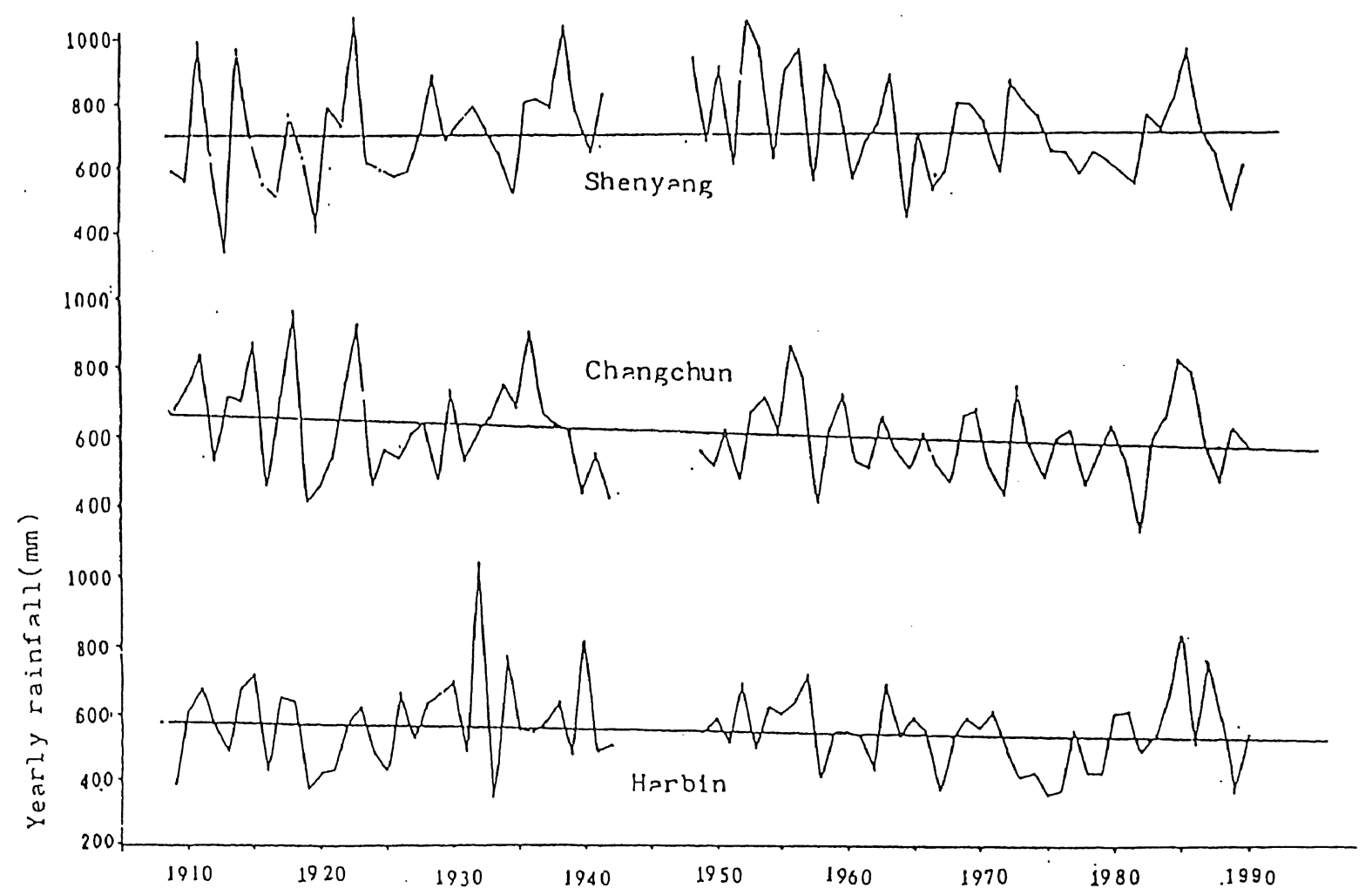

Figure 2. Yearly rainfall (mm) change in years in Shenyang, Changchun and Harbin 